\title{
KNOWLEDGE ABOUT Hypericum perfuratum OF PHARMACISTS FROM PUBLIC AND PRIVATE PHARMACY SERVICES-DISPENSING
}

\author{
Mariela Matachon ${ }^{1}$, Renata Mazuco ${ }^{1}$, Lindiara Campos $^{1}$, Dominik Lenz ${ }^{1}$, Tadeu Andrade ${ }^{1}$, \\ and DENISE ENDRINGER ${ }^{1}$
}

${ }^{1}$ Universidade Vila Velha

May 5, 2020

\begin{abstract}
The Hypericum perforatum, also known as St John's, is mainly used as antidepressive. The objective of this study was to understand the educational level of pharmacists about H. perforatum, including their knowledge about the indication, contraindication, treatment time, adverse effects, pertinent care, and the existence of educational training for pharmacists. A survey was applied on pharmacists to access their knowledge about H. perforatum. The data analysis included the distribution of the relative frequencies and the crossing of the variables for the analysis of the aspects of interest, using the chi-square test and IRAMUTEQ software for discursive questions. Differences were presented regarding the knowledge about the herbal medicine, H. perforatum, among public and private pharmacists, as to the plant's indication, dosage, interactions, adverse effects, and care with the administration. These differences likely stem from variations in age, time of educational formation, and continued education of the professionals interviewed in this study.
\end{abstract}

\section{INTRODUCTION}

Knowledge about plants and their medicinal properties, as well as their use for the purpose of treating and curing diseases, is one of the oldest forms of medicinal practice in world ${ }^{1}$. Since antiquity, myths, legends, and traditions perpetuate the use of medicinal plants and reflect their vast employment in medicine over time $^{2}$.

Although the global market for pharmaceuticals has been predominantly dominated by synthetically derived products $^{3}$, in recent years, there has been an increased investment in the search for alternative medicines and in the therapeutic use of naturally sourced products, particularly plant derivatives ${ }^{4}$. The use of herbal medicines in developed countries constitutes an alternative therapy ${ }^{2}$, however many users believe that because they are naturally sourced, medicinal plants pose no threat to the user's health and are unfortunately unaware that herbal medicines can induce serious adverse effects ${ }^{5}$. In this study, we highlight a plant with significant medical potential,Hypericum perforatum L., an herbaceous, perennial commonly found in Europe, Asia, Brazil, and the USA ${ }^{6}$, where it is commonly known as St. John's wort ${ }^{7}$. Although, H.perforatum is composed of more than 150 compounds with additive, synergistic, and partially antagonistic properties ${ }^{8}$, with the most characteristic of the plant's constituents being naftodiantrones (hypericin and pseudohypercicine), floroglucinols (hyperforin), flavonoids, bioflavonoids, and xanthones ${ }^{9}$. This diversity of medicinally active components and potential utilization e in the treatment of diverse pathologies has sparked significant interest in the medicinal potential of $H$. perforatum.

The action mechanisms of $H$. perforatum have yet to be fully described due to the large abundance and diversity of compounds contained within the plant. Traditional schools of thought have suggested that 
hypericin was the main active ingredient in $H$. perforatum extracts. However, studies have shown that hyperforin is found in concentrations higher than that of hypericin within the plant ${ }^{8}$ and that hyperforin may be primarily responsible for the antidepressant properties attributed to the plant ${ }^{9}$.

Therefore the use of $H$. perforatum extracts have become popular due to the plants' beneficial effects on the nervous system ${ }^{7}$. H. perforatum has been used for decades in clinical practice specifically in the treatment of a range of mood disorders, presenting significant efficacy in the treatment of acute, mild to moderate depression $^{9,10,11,12}$. However, although it has a higher safety profile when compared to conventional antide-

pressants, $H$. perfuratum is not exempt from adverse reactions and drug interactions ${ }^{9,13,14}$. Some adverse side effects attributed to $H$. perfuratum are gastrointestinal symptoms, allergies, dizziness, mental confusion, fatigue, dry mouth and sedation, however these side effects from the use of $H$. perforatum considered to be mild, moderate or transient in nature ${ }^{15}$. Additionally, important interactions are reported with conventional synthetic drugs such as diazepam and paracetamol ${ }^{6}$, antihistamines (fexofenadine), cardiovascular drugs (warfarin), hypolipidemic like simvastatin, gastrointestinal drugs (omeprazole and loperamide), in addition to oral contraceptives, corticosteroids, opioids, antineoplastics, and immunosuppressants ${ }^{8}$.

Considering these aspects, it is important for the health professionals to have in-depth the appropriate knowledge of phytotherapeutics, specifically their interactions and adverse effects, before administering such medicine or conducting a study on the use of these treatments. Among the health professional, pharmacists have a key role in the process of the use of medicine once he is the last link between the prescription and the use of medicine by patients. According to the American Society of Health-System Pharmacists (ASHP), the mission of a pharmacist is to provide pharmaceutical care, which is defined as the direct, responsible provision of medication-related care for the purpose of achieving definite outcomes that improve a patient's quality of life ${ }^{16}$. Therefore, it is of worth importance to develop a study of the use of medicine focused on the knowledge about $H$. perfuratum of pharmacists from public and private pharmacy services-dispensing this herbal medicine

\section{MATERIAL AND METHODS}

\section{Data Collection}

A cross-sectional, descriptive study was developed with the application of structured instruments for data collection and interviews with pharmacists. The research was carried out in the city of Vitória-ES.The data collection was performed over a period of three months, from March 2018 to May 2018. The sample consisted of 29 pharmacists from 29 pharmacies from the Public Health Unit and 29 pharmacists from randomly selected private pharmacies.

\section{Inclusion and Exclusion Criteria}

All pharmacists from the Public Pharmacy (Public Health Unit) in Vitoria ( $\mathrm{n}=29$ ) were included in the sample, and the same quantity $(\mathrm{n}=29)$ were selected of pharmacists from Private Pharmacies, who agreed to participate in the study and signed the Informed Consent Terms.

\section{Ethical Aspects}

The research project was submitted and approved by the Ethics Committee on Research in Human Subjects of Universidade Vila Velha, under protocol n. 2.020.910.

\section{Interview Data}

Structured questionnaires containing discursive and objective questions were used to collect interview data. The structured questionnaires were completed by the pharmacist in the presence of the researcher. The structured questionnaires did not require the identification of the pharmacists, therefore, guaranteeing anonymity. The questionnaire was used to collect the following data: a) socioeconomic data; b) training time; and c) knowledge about medication. The interviews were performed in order to assess the level of instruction about the herbal medicine as well the level of knowledge about indication, contraindication, treatment time, dosage, care in use, and interactions ofH.perforatum . 


\section{Analysis}

Data analysis included the distribution of relative frequencies and the crossing of variables for the analysis of aspects of interest. A Chi-square test was used to compare the proportions obtained in relation to pharmacists' knowledge according to the selected variables.IRAMUTEQ(Interface de $R$ pour les Analyses Multidimensionnelles de Textes et de Questionnaires )software was applied to discursive questions to analyze test data.IRAMUTEQ is a free open source software developed by Pierre Ratinaud ${ }^{17-18}$ and licensed by GNU GPL (v2), which allows for statistical analysis on textual bodies and on individual tables or words. Statistical Package for the Social Sciences (version 17) was used to compile and analyze the data.

\section{RESULTS AND DISCUSSION}

Fifty-eight questionnaires were delivered to 29 pharmacists from the Public Health Units of Vitória and 29 pharmacists from randomly selected Private Pharmacies. Three pharmacists from the Public Health Units and two from Private Pharmacies declined to participate in the survey. Thus based on the inclusion criterion initially established in the study, 26 questionnaires were analyzed from 26 pharmacists in the Public Health Units of Vitória and 27 questionnaires from 27 pharmacists from the Private Pharmacies.

The main results are shown in table 1.In the group of private pharmaciesthe majority of pharmacistswere in the range of 18-30 years old and in the other group were in the range of 31-42 years old. In the Private Pharmacies group, there were no pharmacists over 42 years old, exhibiting that this pharmacies have professionals younger than the Public Health Units group.Oliveira ${ }^{19}$ also found a similar demographic profile, when analyzing the age range of pharmacists in Brazil. The authors identified that the majority of participating professionals were 30 years of age, constituting a young group of pharmacists, trained for a maximum of five years in private college.

In general, the public services there was a higher number of female professionals compared to men, while in private pharmacies the number of women and men was similar. Oliveira ${ }^{19}$ also observed the prevalence of women in the profession while investigating the sociodemographic profile of pharmacists in public and private establishments. In terms of time spent in the pharmacist profession, the majority of Public Health Unit professionals had 11 to 15 years of professional practice, whereas individuals employed by private pharmacies possessed less than a year to 5 years of practice.

In relation to their professional practice, when the pharmacists in the sample were questioned about their knowledge of the phytotherapeutic properties of $H$. perforatum and their indication, the majority of the Public Health Units professionals responded positively to both questions. The pharmacists in the Private Pharmacies group displayed the same results as the Public Health Units group. Considering that the number of samples for each group was nearly the same, with observing only the relative frequencies of each response to the questionnaire, it was observed that the number of participants who possessed limited knowledge of the phytotherapeutic properties of $H$. perforatum was smaller in the Public Health Units group versus the Private Pharmacies group. ( $\left.\mathrm{x}^{2}=22.7985, \mathrm{p}=0.000001\right)$ (Table 1$)$.

The pharmacists of Public Health Units reported knowledge of dosage size and care in the use of H. perforatum . In the Private Pharmacies group less than half of the sample reported knowledge of proper dosage and an even smaller percentage reported possessing knowledge about the care in use of $H$. perforatum . In relation to the pattern observed in the previous responses, professionals in the public sector demonstrateda more advanced knowledge of the utilization and proper dosage of herbal medicines.

Public Health Units participants mentioned several precautions to consider when using $H$. perforatum for medicinal purposes, with several similar warnings being mentioned in more than one questionnaire response. The precautions that were mentioned by at least one interviewee were not to use alcohol, inform the doctor of any adverse reaction, do not exceed the allotted dose of three times a day, do not use for severe depression, do not use during lactation and gestation, and do not mix with another antidepressant. The precautions that were mentioned at least two times were use sunscreen, and do not take continuously. The precautions which was mentioned at least six times was avoid sun exposure and the precaution which was mentioned seven 
times was precaution of interactions with other drugs. The Private Pharmacies group mentioned at least one precaution of being aware of potential drug interactions. Reducing sun exposure while taking $\mathrm{H}$. perforatumwas the most frequent precaution mentioned by the Private Pharmacies group. Finally, concomitant use of another antidepressant, a restriction for diabetics, pregnant women and people using anticonvulsants during the utilization of $H$. perforatum were mentioned at least once in the responses of the private pharmacies group.

In regard to the principle that all pharmacists should be continuously updating their knowledge of pharmaceutical practices ${ }^{18}$, the following question in the questionnaire was related to the professional's knowledge about interactions $H$. perforatum preforms with other drugs. For the Public Health Unit group (n= 25), all participants stated that they had knowledge about the interaction potential of $H$. perforatum. Among the Private Pharmacies group $\left(\mathrm{n}=20\right.$ ), only $25 \%$ reported knowledge of interaction potential. (with a $\mathrm{x}^{2}=$ $111.2139, \mathrm{p}$ value $=0.00000007)($ Table 1$)$.

Concerning the related research on the risks of the use of $H$. perforatum concomitant with other drugs, it is important to note that several authors have described the risks in the use of $H$. perforatum concomitant with other medications, food and other substances ${ }^{12,13,14,21,20,22}$. In regards to which drugs interact with the herbal medicine, the majority of Private Pharmacies did not respond to the question. Pharmacists from the Public Health Units and Private Pharmacies suggested more than one drug has the potential to interact with H. perforatum, with the following cited: immunosuppressors, medicines to treat heart failure, antiretrovirals, antibiotics, antihypertensives, antidiabetics, with five mentions each, anticoagulants, anticonvulsants with six mentions each, and antidepressants and contraceptives with nine mentions each. (Table 1).

Regarding the usual therapeutic indication and dosage, the Public Health Unit group answered that $H$. perforatum acts as an antidepressant and should be administered three times a day and the Private Pharmacies group reported the plant's performance as sedative, antidepressant, and for use in the treatment of symptoms related to menopause. Among the related medicinal properties, the antidepressant effect of this herbal medicine has been of particular interest to the scientific community ${ }^{9}, 1122,23,24$. For example, clinical studies have suggested that aqueous extracts of $H$. perforatum are as effective as synthetic antidepressants and cause fewer side effects ${ }^{7}$. Linde ${ }^{25}$ further claimed that such extracts are comparable to the other forms of antidepressants used in the treatment of mild to moderate depression. The indications and dosages reported by the Public Health Unit group aligned with those referenced in the scientific literature.The indications described by the Private Pharmacies group display that despite the statement that the indication of the herbal medicine is known, respondents stated that $H$. perforatum is utilized in menopausal therapy, which is not in accordance with the official indications presented for the medicinal product.

In the public Health Units, at least half of pharmacists interviewed did not know the indicated dose for this phytotherapic. Similar results were observed in the Private Pharmacies group when pharmacists were questioned about the dosage and indication of the medicine.

The efficacy and tolerance of $H$. perforatum was compared with fluoxetine and placebo for treatment of depression in a double-blind clinical trial lasting over a period of 4 weeks. A demonstrated remission rate was significant for both $H$. perforatum and fluoxetine compared to placebo $(H$. perforatum $24 \%$, fluoxetine $28 \%$ and placebo $7 \%$ ). Phytotherapy was more tolerated than fluoxetine and both medicines were equally effective in short-term treatment ${ }^{23}$. Another study comparing $H$. perforatum fluoxetine, and a placebo sought to evaluate the efficacy of herbal medicine in patients with Major Depressive Disorder, through exploratory analyzes from a double-blind study. The researchers concluded that $H$. perforatum also showed a trend towards greater efficacy compared to fluoxetine and the placebo ${ }^{24}$. However, it was noted in the study that the use of $H$. perforatummight cause adverse side effects.

The European Medicines Agency Committee on Herbal Medicinal Products ${ }^{21}$ reported H. perforatum drug interactions with benzodiazepines, oral contraceptives, antidepressants, voriconazole, methadone, digoxin, theophylline, cyclosporine and finasteride. A study by Mao \&Gubili $2017^{12}$ warned of the interactions between $H$. perforatum, chemotherapeutics, and antidepressants, which 
resulted in their reduced efficacy. There are studies that relate drug interaction with a reduction of plasma levels and interaction with cytochrome $\mathrm{P} 450^{12,14,21,22,26}$, Interactions have been reported particularly with drugs, which are a substrate of cytochrome P450 (CYP), which are enzymes that are common sites of drug interactions in humans, and P-glycoprotein which is one of the most clinically important transmembrane transporters in humans. Clinical studies suggest that $H$. perforatum may modulate CYP activity and has been shown to lower plasma concentration of well-known P-glycoprotein substrates, including digoxin, fexofenadine, and talinolol ${ }^{14}$.

The result found in the textual analysis with the calculation of frequency of words is shown in figure 1

In relation to knowledge of the adverse side effects of $H$. perforatum, the Public Health Unit professionals reported not knowing of any adverse effects but suggested at least one of the following:dizziness,dry mouth, increased pressure and skin blemishes, allergic reactions, gastrointestinal irritations, and photosensitivity. In the Private Pharmacies group, the majority did not respond and a percentage suggested at least one of the following adverse effects: dizziness, dry mouth, nausea, fatigue, swelling in the legs, drowsiness, intoxication, allergic reactions, and, gastrointestinal irritations. Comparing the adverse effects mentioned by both groups, no adverse effects of $H$. perforatum use were found in the literature. As described by Henderson et al. $2002^{15}$, the known adverse effects are gastrointestinal symptoms, allergies, dry mouth, mental confusion, fatigue, dizziness, and sedation with each adverse effect existing in the mild to moderate, or even transient range. Such scientific descriptions corroborate with that described by both sample groups. The analysis of the response from both sample groups suggests that knowledge of the adverse effects of $H$. perforatum use is still low. According to a review by the European Medicines Agency $(2009)^{21}$, the adverse side effects of $H$. perforatum are nausea, headache, dizziness, pain, melancholia, heart palpitation, abdominal pain, insomnia, diarrhea, acute deterioration, dry mouth, allergic reaction to sunlight, asthenia, sweating, somatic disorder, cerebral hemorrhage, autonomic nervous system disorder, skin and appendage disorders, sleep disturbance, sexual problems, forgetfulness, ear and labyrinth disorders, frequent urination, blurred vision, tremor muscle spasms, muscle joint stiffness, lack of appetite, fatigue, bronchitis, influenza-like symptoms, cough, infection, drowsiness, constipation, pruritus, restlessness, tremor, and gastrointestinal disorders. Among these listed side effects, at least five were mentioned by five of the interviewees in this study.

In order for pharmacists to be able to guide the use and care ofH. perforatum, it is necessary for pharmacists to obtain and maintain knowledge about the drug, including knowledge of the adverse side effects and interactions. From the Public Health Unit group, most professionals affirmed having learned about $H$. perforatum in continuing education training and most of Private Pharmacies reported having learned about the $H$. perforatum drug through family tradition, an educational training course, popular knowledge, and academic knowledge.

In the Public Health Units group the greatest source of information was in the form of an educational training course.In the Private Pharmacies group, the majority stated that the academic medium and popular knowledge as sources of information about $H$. perforatum. Popular wisdom is commonly used to obtain information on indications of use, efficacy, and safety of medicinal plants and herbal medicines ${ }^{27}$. However, randomized, double-blind, and controlled clinical trials conducted with herbal medicines provide new insights and are recent reliable sources of information with methodological standards that can reduce risks and uncertainties ${ }^{27}$. Access to this information is provided through training courses, which are unfortunately becoming increasingly scarce. Oliveira ${ }^{17}$ observed that the percentage of interviewed pharmacists who received training was nearly equivalent to those who rarely received formal training. It is clear that professionals working in public pharmacies receive continuing education in service, while professionals working in private pharmacies rely on familial and popular knowledge, but still seek extension courses to update themselves, and a percentage reported having received the knowledge during the training period of their occupation.

Pharmacists were also asked to keep up to date on the innovations and recent events in the field of herbal medicines. Pharmacists in thePublic Health Units group mentioned at least one of the following sources to remain current in the field of herbal medicine: popular journals and magazines, educational courses, continuing education, and academic journals. The Private Pharmacies professionals cited at least one of 
the following sources: educational courses, permanent education, newspapers, and popular magazines and journals (Table 1$)$.

Heckler ${ }^{28}$, when analyzing the profile of 20 pharmacists, suggested that they used books, information from suppliers, and the internet as a sources of information about herbal medicines. However, it is important to note that the books mentioned are national and often package inserts and manuals that contain a restricted information about the medicine and cannot be supported by the pharmacist. Rates ${ }^{29}$ affirmed that the prevalence of this type of reading has been considered a determinant for the poor quality of information provided to the user of the herbal medicine.

The basic elements of primary and pharmaceutical care are similar and both fields include care centered around the patient, knowledge about the treatment of acute and chronic disorders, prevention of injuries, effective documentation service delivery, universal access, ongoing care and systematically integrality of care, the responsibility for treatment, including correct guidance with follow up of the user treatment, and promotion of education and health ${ }^{30}$.

The professionals from both groups affirmed that they did not follow up with users during their treatment with the medicine $H$. perforatum, but pharmacists from both groups provided information to users about the mode of use, interactions, and side effects. According to Kirby ${ }^{31}$ patients' knowledge of their condition and disease improves adherence to treatment and are among the strategies to promote the rational use of medicines, with pharmaceutical counseling being one of these measures. Glaeser ${ }^{32}$ stated that pharmacists are the most available health professionals for the general population and are as relevant to patient care as the services provided by other less available health professionals. When asked about what makes the users' orientation difficult, the majority of pharmacists indicated the lack of pharmacy structure and the lack of user knowledge.

In a general evaluation, respecting the limit of the research and the sample number obtained, greater knowledge about the herbal medicine H. perofatum by the pharmacists in Public Health Units was evident with a $\mathrm{p}$ value $<0.05$. Silva et al. ${ }^{33}$ emphasized that little attention is given to the development of communication skills, a fundamental point for this practice within pharmacies, however, they concluded that it is possible to develop them continuously, through lifelong education or in-service training. Based on data similar to Silva et al. ${ }^{33}$ Vitoria's authorities implemented a course of continuing education for the pharmacists from Public Health Units. It is possible that the policies implemented by the municipality may be responsible for the current level of knowledge about H.perforatum in the Public Health Units group.

The results suggest that pharmacists in Public Health Units receive more information and obligatorily follow protocols for dispensing, whereas in private pharmacies the pharmacist must obtain knowledge through extension courses or postgraduate courses, contrary to pharmacists in Public Health Units who receive continuing education in service.

\section{CONCLUSION}

It was observed that potentially the pharmaceutical professionals of the Public Health Units possess a greater understanding of the herbal medicine $H$. perforatum, the medicine's active principle, mechanisms of action, posology, adverse effects, and drug interactions, as opposed to Private Pharmacies professionals. This discrepancy could possibly be due to the actions and public policies implemented by the Health Department in the Municipality of Vitória, which include, among other practices, a Permanent Education program for dispensing herbal medicines. However, even with the program, many professionals still do not feel prepared for this type of dispensation and the deficient communication between pharmacist and user requires attention from the public and private sectors.

\section{Acknowledgments}

To the pharmacy professionals of the Health Units of the Municipality of Vitória. The authors thank the National Council for Scientific and Technological Development (CNPq) for their financial support. 


\section{DISCLOSURE/CONFLICT OF INTEREST}

There is no conflict of interests.

\section{REFERENCES}

1. Gadelha CS, Pinto Junior VM, Bezerra KKS, Pereira BBM, Maracajá PB. Estudo bibliográfico sobre o uso das plantas medicinais e fitoterápicos no Brasil. Rev Verde . 2013; 8(5): 208 - 212.

2. Ibiapina WV, Leitão BP, Batista MM, Pinto DS. Inserção da fitoterapia na atenção primária aos usuários do SUS. Rev Cienc Sau Nova Esperança . 2014; 12 (1): 58-68.

3. Nascimento JE, Lacerda EU, Nascimento VT, Melo JG, Alves BS, Silva LGM et al. Produtos à base de Plantas Medicinais comercializados em Pernambuco - Nordeste do Brasil. Acta Farm. Bonaerense. 2005; 24(1): 113-22.

4. Lall N, Kishore NJ. Are plants used for skin care in South Africa fully explored? Ethnopharmacolog . $2014 ; 153(1): 61-84$.

5. Fontenelle RP, Sousa DMP de, Carvalho ALM, Oliveira FA. Fitoterapia na Atenção Básica: olhares dos gestores e profissionais da Estratégia Saúde da Família de Teresina (PI), Brasil. Ciênc. Saúde Coletiva . 2013; 18(8): 2385-2394.

6. Raskovic A, Cvejić J, Stilinović N, Goločorbin-Kon S, Vukmirović S, Mimica-Dukić N, et al. Interaction between different extracts ofHypericum perforatum L. from Serbia and pentobarbital, diazepam and paracetamol. Molecules . 2014; 19 (4): 3869-82.

7. Alves ACS; Moraes DC.; De Freitas GBL; Almeida DJ. Aspectos botânicos, químicos, farmacológicos e terapêuticos do Hypericum perforatumL. RevBrasPl Med ., 2014; 3 (16), 593-606.

8. Russo E, Scicchitano F, Whalley BJ, Mazzitello C, Ciriaco M, Esposito S, et al. Hypericumperforatum: pharmacokinetic, mechanismofaction, tolerability, andclinicaldrug-druginteractions. Phytother Res . $2013 ; 28(5): 643-55$.

9. Seifritz E, Hatzinger M, Holsboer-Trachsler E. Efficacy ofHypericum extract WS(@) 5570 compared with paroxetine in patients with a moderate major depressive episode - a subgroup analysis. Int $J$ PsychiatryClinPract . 2016; 20(3): 126-32.

10. Barbui C; Cipriani A, Patel V, Ayuso-Mateos JL, Ommeren MV. Efficacy of antidepressants and benzodiazepines in minor depression: systematic review and meta-analysis. Br. J. Psychiatry. 2011 jan; 198(1): 11-16.

11. Bukhari IA, Dar A. Behavioral profile of Hypericum perforatum(St. Jonh's Wort) extract. A comparison with standartantodepressants in animal models of depression. European Review for Medical andPharmacologicalSciences . 2013, 17: 1082-1089.

12. Mao JJ, Gubili J. St. John's Wort. The ASCO Post. Dec., 2017. 1-9. Avaliable in www.ascopost.com/issues/december-25-2017/st-john-swort/ acces in 01/31/2019.

13. Izzo AA. Drug interactions with St. John's Wort (Hypericum perforatum ): An review of clinical evidence. Int J Clin PharmacolTher. 2004 Mar;42(3):139-48.

14. Borrelli F, Izzo AA. Herb-Drug Interactions with St John's Wort (Hypericum perforatum ): an Update on Clinical Observations. The AAPS Journal . 2009. 11(4): 710-7 ${ }^{27}$.

15. Henderson L, Yue QY, Bergquist C, Gerden B, Arlett P. St John's wort (Hypericum perforatum ): drug interactions and clinical out comes. Br J Clin Pharmacol. 2002; 54(4): 349-56

16. Sartore ME, Ehman KM, Good CB. The Significance os Pharmacy Interventions: An update review in the presence of electronic order entry. The American Journal of Pharmacy Benefits . Mar/apr., 2017. 6 (2): 24-30

17. Ratinaud, P., \& Marchand, P. (2012). Application de laméthode ALCESTE à de "gros" corpus et stabilitédes "mondes lexicaux" : analysedu "CableGate" avecIraMuTeQ. Em: Actes des 11eme Journeesinternationalesd'Analysestatistique des DonneesTextuelles (835-844). Presented at the 11eme Journeesinternationalesd'Analysestatistique des DonneesTextuelles. JADT 2012, Liege

18. Camargo BV; Justo AM. Tutorial para uso do software de analise textual IRAMUTEQ. Universidade Federal de Santa Catarina. Santa Catarina, 2013.

19. Oliveira NVBV, Szabo I, Bastos LL, Paiva SP. Atuacao profissional dos farmaceuticos no Brasil: perfil 
sociodemografico e dinamica de trabalho em farmacias e drogarias privadas. Revista Saude Soc . 2017; 4(26): 1105-1121.

20. FIP (FEDERATION INTERNATIONALE PHARMACEUTIQUE). Buenas Practicas de Farmacia: Normas para la calidad de los servicios farmaceuticos. PO Box 84200. 2508. Viena, 2000.

21. European Medicines Agency.Commitee on Herbal Medicinal Products. (HMPC). Assessment Reporto n Hypericum perforatum L., Herba. London, 2009, 77p.

22. Bongiorno P, LoGiudice P. Hypericum for depression. Natural Medicine Journal. 2010. 2(12).

23. Rahimi R, Nikfar S, Abdollahi M. Efficacy and tolerability ofHypericum perforatum in major depressive disorder in comparison with selective serotonin reuptake inhibitors: A meta-analysis.NeuroPsychopharmacology\&BiologicalPsychiatry . 2009. 33: 118-127.

24. Rapaport MH, Nierenberg AA, Howland R, Dording C, Schettler P, Mischoulon D. The treatment of minor depression with St.John's Wort os Citalopram: Failure to show bennefit over placebo. J. Psychiatr. Res . 2001, july, 45 (7): 931-941.

25. Linde K, Berner MM, Kriston L. St John's Wort for Depression: meta-analysis of randomised controlled trials. Br J Psychiatry . 2005; 86: 99-107.

26. Azeredo FJ, Uchoa FT, Dalla Costa T. Papel da Glicoproteina-P na Farmacocinetica e nas Interacoes Medicamentosas. Rev. Bras. Farm . 2009. 90(4): 321-326.

27. Melo DO, Castro LLC. A contribuicao do farmaceutico para a promocao do acesso e uso racional de medicamentos essenciais no SUS. Rev.Ciencia \& Saude Coletiva , 2017, 22(1):235-244.

28. Glaeser H, Bailey DG, Dresser GK, Gregor JC, Schwarz UI, McGrath JS et al. Intestinal drug transporter expression and the impact of grapefruit juice in humans. Clin PharmacolTher . 2007;81(3):36270.

29. Silva EV, Alves JOS, Vidal JO. O papel do farmaceutico comunitario no aconselhamento ao paciente. Boletim Farmacoterapeutica. 2008;4.

30. Brasil. Politica Nacional de Praticas Integrativas e Complementares (PNPIC) no Sistema Unico de Saude. Brasilia: Ministerio da Saude, 2006.

31. Brasil. Anvisa. Agencia Nacional de Vigilancia Sanitaria. Momento Fitoterapico: Farmacopeia Brasileira. Brasilia: Ministerio da Saude, 2016. Disponivel em: http://portal.anvisa.gov.br/documents/33832/2909630/Memento+Fitoterapico/a80ec477-bb364ae0-b1d2-e2461217e06b. Acesso em 10/10/2018.

32. Badke MR, Budo MLD, Silva FM, Ressel LB. Plantas medicinais: o saber sustentado na pratica do cotidiano popular.Esc Anna Nery , 2011;1(15): 132-139.

33. Benini EB, Sartori MAB, Busch GC, Rempel C, Schultz G, Strohschoen AAG. Valorizacao da flora nativa quanto ao potencial fitoterapico.Rev Destaques Academicos . 2010; 2(3): 11-17.

34. Bjerkenstedt L, Edman GV, Alken RG, Mannel M. Hypericum extract LI 160 and fluoxetine in mild to moderate depression: a randomized, placebo-controlled multi-center study in outpatients. Eur Arch Psychiatry Clin Neurosci ., 2005; 255 (1): 40-7.

35. Murck H, Fava M, Alpert J, Nierenberg AA, Mischoulon D, Otto MW, et al. Hypericum extract in patients with MDD and reversed vegetative signs: re-analysis from data of a double-blind, randomized trial ofhypericum extract, fluoxetine, and placebo. Int J Neuropsychopharmacol . 2005; 8(2): 215-21.

36. Lahlou, S. Text Mining Methods: An answer to Chartier and Meunier. Paperson Social Representations, 2010; 20 (38), 1.-7.

37. Brasil. Anvisa. Agencia Nacional de Vigilancia Sanitaria. Resolucao RDC no 44, de 17 de agosto de 2009. Diario Oficial da Uniao, Brasilia (DF): 2009, secao 1, p. 78.

38. Heckler APM, AndreazzaDall'agnol RS, Heineck I, Rates SMK. Estudo Exploratorio sobre a Dispensacao de Fitoterapicos e Plantas Medicinais em Porto Alegre/RS. Acta Farm Bonaerense . $2005 ; 24$ (2): $277-283$.

39. Rates SMK. Promocao do uso racional de fitoterapicos: uma abordagem no ensino da Farmacognosia. Rev. Bras. Farmacog. 2001; 2(11): 57-69.

40. Kirby BJ, Unadkat JD. Grapefruit juice, a glass full of drug interactions? Clin PharmacolTher. 2007; 81(5): 631-633. 
41. Negrelle RRB, Tomazzoni MI, Ceccon MF, Valente TP. Estudo etnobotanico junto a Unidade Saude da Familia Nossa Senhora dos Navegantes: subsidios para o estabelecimento de programa de fitoterapicos na Rede Basica de Saude do Municipio de Cascavel (Parana). Ver.Bra. Pl. Med . 2007; 3 (9): 6-22.

42. Antonio GD, Tesser CD, Moretti-Pires RO. Fitoterapia na atencao primaria a saude. Rev SaudePublica , 2014; 48 (3), 541-553.

43. Vitoria. Secretaria Municipal de Saude. Conselho Municipal de Saude. Resolucao n. 1.019, de 20 de outubro de 2015. Aprova o Documento Tecnico da Politica Municipal de Institucionalizacao de Praticas Integrativas e Complementares de Vitoria-ES, com base no parecer da Comissao de Atencao a Saude do Conselho Municipal de Saude de Vitoria. Vitoria, ES, 2015.

\section{Hosted file}

TABLE_1.docx available at https://authorea.com/users/298938/articles/428320-knowledge-abouthypericum-perfuratum-of-pharmacists-from-public-and-private-pharmacy-services-dispensing

\section{Hosted file}

Figure_1.docx available at https://authorea.com/users/298938/articles/428320-knowledge-abouthypericum-perfuratum-of-pharmacists-from-public-and-private-pharmacy-services-dispensing 